\title{
Salários, produtividade e lucros na indústria brasileira, 1945-1978
}

RENATO PERIM COLISTETE*

Wages, productivity and profits in the Brazilian manufacturing industry, 1945-1978. This article investigates the distribution between profits and wages in Brazil's manufacturing industry from 1945 to 1978 . First, the article provides yearly series of average real wages and labour productivity, from which labour unit costs and the distribution between profits and wages in the manufacturing industry are estimated. Second, the article addresses the behaviour of wages, labour productivity and industrial income distribution in the context of variable economic, political and institutional conditions which prevailed in post-war Brazil. The results of the quantitative analysis allow us to assess both the trends and the yearly behaviour of the manufacturing income distribution during a key period of the Brazilian economic history.

Keywords: Productivity; income distribution; post-war industrial growth; Brazil.

JEL Classification: N36.

O desempenho da economia brasileira entre meados da década de 1940 e final da década de 1970 tem sido visto como um dos casos mais representativos do crescimento econômico no pós-guerra. Além da notável expansão econômica, uma outra característica da experiência brasileira foi o elevado nível de concentração de renda. ${ }^{1}$ O Brasil tornou-se, com outros países latino-americanos e da África Subsaariana, uma das poucas áreas do globo em que não houve uma substancial melhora na distribuição de renda nos trinta anos após o fim da Segunda Guerra

\footnotetext{
* Departamento de Economia, FEA-USP. E-mail: rcolistete@usp.br. Agradeço a Claudio Shikida, Felipe Loureiro, Jaylson Silveira, Gustavo Barros, Michel Marson, a um parecerista anônimo desta Revista e aos participantes dos seminários de História Econômica da Universidade Nacional do Uruguai e da Escola de Economia da Fundação Getulio Vargas-São Paulo, pelos valiosos comentários e sugestões. Submetido: Novembro 2007; Aprovado: Maio 2008.
}

${ }^{1}$ Fishlow \& Cardoso (1992); Maddison et al. (1992); e Thorp (1998). 
Mundial. ${ }^{2} \mathrm{O}$ motor das transformações econômicas no Brasil no pós-guerra foi o setor industrial, que cresceu em média 9,0\% a.a. entre 1945 e 1978, superando por ampla margem o observado nas maiores economias da América Latina. ${ }^{3}$ Visto que a elevada desigualdade na distribuição de renda foi uma característica do crescimento econômico brasileiro após 1945, caberia então perguntar: como a renda gerada na indústria foi repartida entre trabalhadores (salários) e empresas (lucros)? Ou ainda, em que medida a distribuição entre salários e lucros industriais no contexto da industrialização acelerada pode ter acompanhado a tendência da distribuição de renda em geral no Brasil do pós-guerra?

A evolução da repartição de renda no setor industrial foi objeto de análise em vários trabalhos importantes nas décadas de 1970 e $1980 .{ }^{4} \mathrm{O}$ presente artigo segue a tradição desses estudos, consistindo em uma tentativa de sistematização de dados e análise quantitativa sobre a distribuição da renda entre lucros e salários na indústria manufatureira do Brasil entre 1945 e 1978. O trabalho concentra-se em dois períodos básicos (1945-1964 e 1965-1978) e em intervalos delimitados pelos governos do pós-guerra, indo do término do Estado Novo em 1945 até o último ano do governo Geisel em 1978.

$\mathrm{O}$ artigo divide-se em seis seções além desta introdução. As primeira e segunda seções tratam do comportamento dos salários industriais entre 1945-1964 e 1965-1978, relacionando os resultados observados às políticas governamentais. A terceira seção apresenta estimativas dos custos unitários do trabalho e da participação relativa dos salários na renda industrial. As quarta e quinta seções trazem uma discussão detalhada das tendências dos custos unitários do trabalho e da distribuição nos períodos 1945-1964 e 1965-1978. A última seção conclui o artigo.

\section{SALÁRIOS INDUSTRIAIS NO PERÍODO 1945-1964}

A Tabela 1 apresenta os salários médios reais do pessoal ligado à produção ocupado na indústria manufatureira no Brasil entre 1945 e 1978, obtidos com a utilização de três índices de preços: (1) Índice de Preços ao Consumidor do Ministério do Trabalho (IPC- MTb); (2) Índice de Preços ao Consumidor da Prefeitura de São Paulo/Instituto de Pesquisas Econômicas-USP (IPC-SP) e (3) Índice de Preços ao Atacado, Disponibilidade Interna, da Fundação Getulio Vargas (IPA-DI). ${ }^{5}$ Quan-

\footnotetext{
${ }^{2}$ Altimir (1996), p. 48; Barros et al. (1997), pp. 22-27; Cornia \& Addison (2003); Deininger \& Squire (1996), p. 576; Fishlow (1973), p. 10; Hoffman (2001), pp. 68-70; e Maddison et al. (1992), pp. 10-16.

${ }^{3}$ Calculado a partir dos dados da Oxlad (Oxford Latin American Economic History Database) disponíveis em http://oxlad.qeh.ox.ac.uk/.

${ }^{4}$ Ver Considera (1980); Fishlow (1973), p. 29; Lago et al. (1979), pp. 123-124, 173-174; Mata \& Bacha (1973), pp. 327-332; Saboia (1990), pp. 588-590; Ócio (1986); Tavares \& Souza (1981), pp. 22-25; e Wells (1974), p. 10.
}

${ }^{5}$ Ver Apêndice para detalhes. 
do utilizados para deflacionar os salários, os índices de preços ao consumidor definem o chamado "salário-consumo" real, que é a medida relevante para avaliar o poder de compra dos salários e, assim, a percepção dos trabalhadores quanto às suas condições de vida (Carlin \& Soskice, 2006, p. 107). Apesar de sua cobertura nacional, a série do IPC-MTb apresenta problemas metodológicos, motivo pelo qual utiliza-se o IPC-SP para comparações.

Já o IPA-DI (Tabela 1, página seguinte, coluna 3), calculado pela Fundação Getulio Vargas, exclui as fases de comercialização posteriores à venda no atacado, aproximando-se de uma medida dos preços de venda do produto final e de compra de insumos pelas empresas produtoras. Utilizando o IPA-DI como deflator dos salários, chega-se a uma medida do "salário-produto" real, que é a variável relevante para as firmas em suas decisões de contratar trabalho. ${ }^{6}$ A Tabela 1 também apresenta os dados de produtividade de trabalho (coluna 4), que serão discutidos posteriormente.

A análise aqui realizada concentra-se no pessoal ligado à produção, cuja definição pelo IBGE foi modificada a partir de 1963, como será visto adiante. Dessa forma, o termo "salários" refere-se aos rendimentos do pessoal ligado à produção, sendo os "lucros" definidos como um resíduo que abrange inclusive os salários do pessoal ligado à administração. Essa é uma simplificação necessária, pois não há meios de separar as remunerações de proprietários, diretores e sócios, que se confundem com os lucros das empresas, dos salários dos empregados de escritório. ${ }^{7}$ As fontes e os procedimentos realizados para o encadeamento dos dados dos Censos Industriais, Registros Industriais e Pesquisas Industriais são descritos no Apêndice. ${ }^{8}$

Os dados apresentados na Tabela 1 apontam para a ocorrência de um ajuste nos mercados de trabalho no imediato pós-Segunda Guerra Mundial no Brasil. Após um aumento de 12,7\% entre 1945 e 1946, o salário-consumo real caiu 10,8\% em 1947 e somente recuperou seu nível anterior em 1949-1950 (ver Tabela 1, séries 1-2). ${ }^{9}$ Já o salário-produto (Tabela 1, série 3) apresentou taxas positivas de crescimento, com desaceleração em 1947 (6,9\%) e 1948 (4,7\%) em comparação a 1946 $(13,3 \%)$. Tais resultados parecem ter estreita relação com as políticas macroeconômicas deflacionárias adotadas pelo governo Dutra (janeiro 1946 - janeiro 1951) a partir de 1947, quando a economia brasileira passou a enfrentar sérios problemas de escassez de dólares e aguda crise cambial (Vianna, 1990). Além disso, o governo

\footnotetext{
${ }^{6}$ Carlin \& Soskice (2006), p. 107. Para estudos que utilizaram a medida de salário-produto no Brasil, ver Bacha (1979); Mata \& Bacha (1973); e Wells (1974).

${ }^{7}$ Os dados oficiais de salários incluem despesas com previdência e assistência social, bonificações, $13^{\circ}$ salário (a partir de 1962) e comissões e ajudas de custo; ver Brasil (1990), p. 370.

${ }^{8}$ Ver também Considera (1980); Mata \& Bacha (1973); Souza \& Baltar (1979); e Wells (1974; 1983).

${ }^{9}$ Conforme explicado no Apêndice, os salários das séries 1 e 2 da Tabela 1 foram deflacionados pelo mesmo índice de preços entre 1945 e 1948.
} 


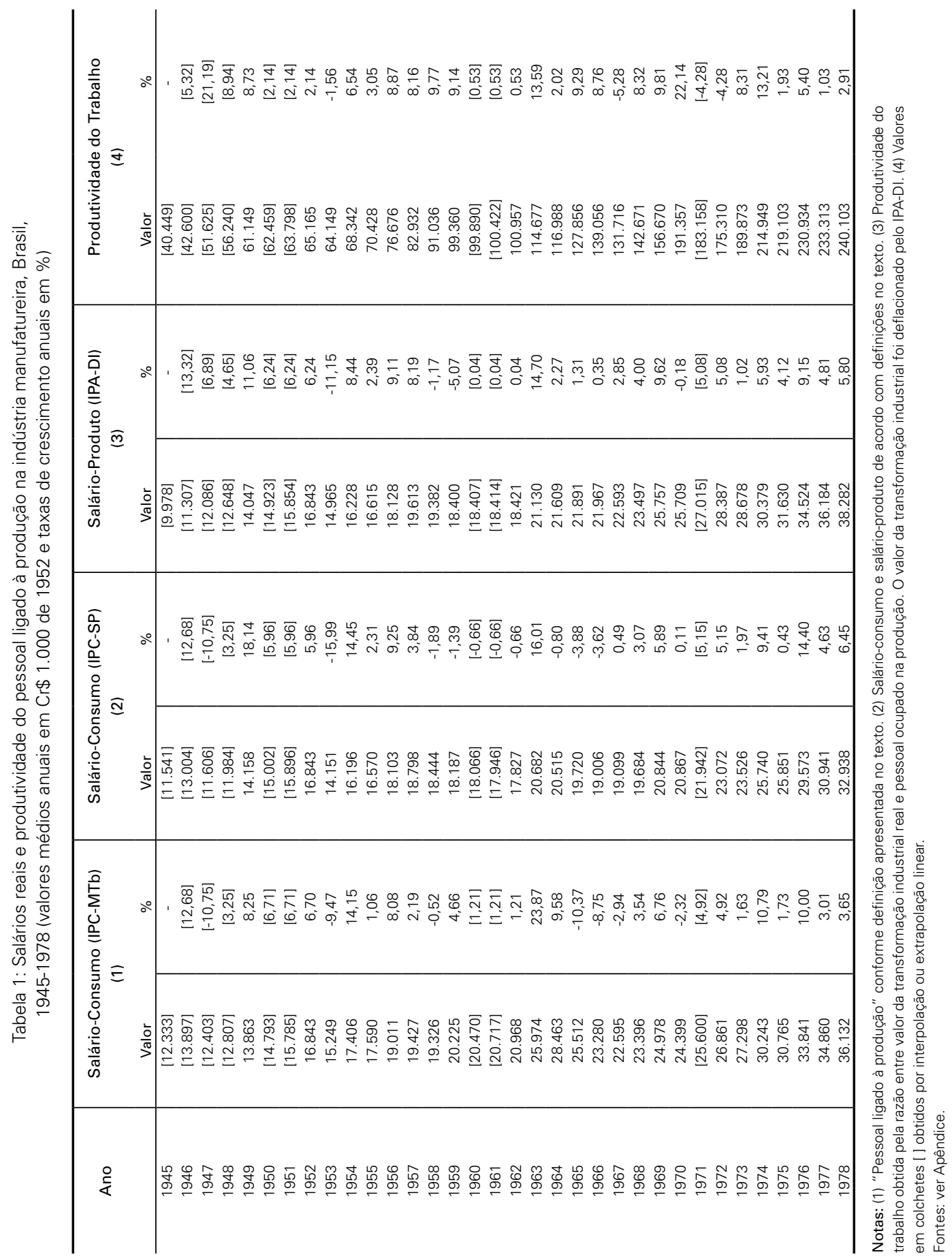


Dutra lançou uma ofensiva contra o movimento sindical que havia começado a reorganizar-se após o fim da ditadura do Estado Novo, em outubro de $1945 .^{10}$

Por outro lado, a recuperação dos salários industriais após 1947, sob condições institucionais desfavoráveis para a organização dos trabalhadores, pode ser considerada um resultado relativamente inesperado. Ainda mais quando se recorda que o salário mínimo oficial não foi reajustado durante todo o governo Dutra (Lago et al., 1979, p. 96). O salário-consumo cresceu em média 1,9\% a.a. quando deflacionado pelo IPC-MTb e 4,2\% a.a. se deflacionado pelo IPC-SP entre 1947 e 1950, enquanto o salário-produto (deflacionado pelo IPA-DI) cresceu 7,2\% a.a. no mesmo período (Tabela 1). Esses percentuais constituem evidências de que outros fatores, não relacionados às condições políticas que afetaram negativamente o poder de barganha dos trabalhadores, tiveram impacto sobre os salários industriais (Colistete, 2001, p. 47-50; Wells, 1983, p. 301).

A eleição de Getulio Vargas no final de 1950 deu alento às expectativas de um rápido crescimento dos salários dos operários. Como é possível ver na Tabela 1 , porém, o comportamento dos salários foi irregular durante o governo Vargas (janeiro 1951 - agosto 1954): quando deflacionados respectivamente pelo IPC-MTb e IPC-SP, houve crescimento médio de 6,7 \% e 6,0\% a.a. entre 1950 e 1952, seguido de uma queda de $-9,5 \%$ e $-16,0 \%$ em 1953 e outra elevação de $14,1 \%$ e $14,5 \%$ em 1954. O salário-produto, deflacionado pelo IPA-DI, cresceu 6,2\% entre 1950 e 1952, declinou -11,2\% em 1953 e voltou a crescer 8,4\% em 1954. Parece que, a despeito das tentativas de Vargas de obter suporte popular, os benefícios para os trabalhadores industriais durante seu governo foram relativamente limitados em termos de crescimento do salário real. ${ }^{11}$

Um padrão similar ao do período Vargas foi observado durante a presidência de Juscelino Kubitschek (janeiro 1956 - janeiro 1961). Se forem considerados os níveis dos salários entre o início e o final do governo Kubitschek, o balanço foi apenas moderadamente positivo para as remunerações do trabalho no caso da série deflacionada pelo IPC-MTb (com salários industriais 7,7\% maiores em 1960 em relação a 1956). Com o uso do IPC-SP como deflator, ao final do governo Kubitschek o salário-consumo foi inferior em - $0,2 \%$ do registrado em 1956. Do ponto de vista das empresas, o salário-produto teve um comportamento favorável, pois cresceu apenas 1,5\% em 1960 em relação a 1956 (Tabela 1).

Uma avaliação das tendências nos salários reais durante os governos de Jânio Quadros (janeiro 1961 - agosto 1961) e João Goulart (setembro 1961 - março 1964) é prejudicada por problemas nas estatísticas disponíveis. Primeiro, o IBGE não realizou em 1960 e 1961 pesquisas industriais similares às conduzidas em anos anteriores. Segundo, houve mudança no conceito de pessoal ocupado pesquisado pelo IBGE a partir de 1963. Até 1962 o pessoal empregado foi dividido em "pessoal ligado à administração" (proprietários, diretores, sócios, empregados de escritório,

\footnotetext{
${ }^{10}$ Colistete (2001), pp. 47-49. Ver também Wells (1983), tabela 1, pp. 298-299.

${ }^{11}$ Conforme sugerido também por Wells (1983), p. 301.
} 
técnicos e engenheiros) e "pessoal ligado à produção" (operários, mestres e contramestres). De 1963 em diante, técnicos e engenheiros passaram a ser classificados ao lado de operários, mestres e contramestres sob o título de pessoal ligado à produção. Uma vez que a mudança na classificação tende a elevar os salários do pessoal ligado à produção, a comparação entre os valores das séries antes e depois de 1963 fica prejudicada (Lago et al., 1979, pp. 150-151).

A ausência de dados para os anos de 1960 e 1961 pode ser parcialmente contornada por interpolação linear. Um problema mais difícil diz respeito à mudança na classificação do pessoal ocupado. Infelizmente não há uma base segura para decompor o efeito da mudança metodológica nas pesquisas industriais oficiais em 1963. Uma opção é realizar estimativas a partir de alguma hipótese plausível. Pode-se considerar, por exemplo, que a razão entre salários pagos aos operários (operários, mestres e contramestres) e os pagos ao pessoal ocupado total em 1963 e 1964 foi a mesma observada em 1962, último ano antes da mudança metodológica. A Tabela 2 apresenta os valores estimados em 1963 e 1964, dada a razão de $82,1 \%$ observada entre os salários dos operários e os do pessoal ocupado total em 1962 , podendo tais valores ser considerados o limite superior dos salários reais dos operários na indústria manufatureira em 1963 e 1964.

Tabela 2: Estimativas dos salários dos operários ocupados na indústria manufatureira, Brasil, 1962-1964 (salários anuais, valores em $\operatorname{Cr} \$ 1.000$ de 1952)

\begin{tabular}{c|c|c|c|c|c|c}
\hline \multirow{2}{*}{ Ano } & \multicolumn{2}{|c|}{$\begin{array}{c}\text { Salário-Consumo } \\
\text { (IPC-MTb) } \\
(1)\end{array}$} & \multicolumn{2}{c|}{$\begin{array}{c}\text { Salário-Consumo } \\
\text { (IPC-SP) } \\
\text { (2) }\end{array}$} & \multicolumn{2}{|c}{$\begin{array}{c}\text { Salário-Produto } \\
\text { (IPA-DI) } \\
\text { (3) }\end{array}$} \\
\cline { 2 - 7 } & $\begin{array}{c}\text { Valor } \\
\text { limite } \\
\text { superior }\end{array}$ & $\begin{array}{c}\text { Valor } \\
\text { limite } \\
\text { inferior }\end{array}$ & $\begin{array}{c}\text { Valor } \\
\text { limite } \\
\text { superior }\end{array}$ & $\begin{array}{c}\text { Valor } \\
\text { limite } \\
\text { inferior }\end{array}$ & $\begin{array}{c}\text { Valor } \\
\text { limite } \\
\text { superior }\end{array}$ & $\begin{array}{c}\text { Valor } \\
\text { limite } \\
\text { inferior }\end{array}$ \\
\hline 1963 & 24.813 & 24.162 & 19.757 & 19.239 & 20.185 & 19.656 \\
1964 & 27.171 & 25.730 & 19.584 & 18.546 & 20.628 & 19.534 \\
\hline
\end{tabular}

Fonte: Ver texto.

Há um problema na estimativa anterior porque a razão entre salários dos operários e salários do pessoal ocupado total declinou no período. Uma estimativa do que poderia ser o limite inferior dos salários industriais em 1963-1964 pode ser obtida adotando uma perspectiva mais pessimista sobre a evolução dos salários dos operários na época: se a queda na razão salários dos operários/salários do pessoal ocupado total entre 1959 e 1962 for considerada como uma tendência no período, aquela razão teria declinado $-2,8 \%$ a.a. em 1963 e 1964 no caso da série 1, IPC-MTb, por exemplo. ${ }^{12} \mathrm{~A}$ Tabela 2 apresenta os resultados desse exercício para todas as séries de salários industriais (ver coluna "Valor limite inferior").

\footnotetext{
${ }^{12}$ A porcentagem de $-2,8 \%$ foi obtida pelo cálculo da taxa composta de crescimento das razões salário operários/salário pessoal ocupado total entre 1959 e 1962.
} 
Nas estimativas do limite superior da Tabela 2, os níveis dos salários industriais em 1964 situaram-se 31,2\% acima dos rendimentos do trabalho em 1961 no caso da série 1 (IPC-MTb), 9,1\% na série 2 (IPC-SP) e 12,0\% na série 3 (IPA-DI). Com os dados estimados do limite inferior da Tabela 2, os salários industriais em 1964 apresentaram os seguintes aumentos em relação a 1961: 24,2\% (IPC-MTb), 3,3\% (IPC-SP) e 6,1\% (IPA-DI). Esses percentuais são significativamente menores do que os obtidos com os dados sem ajustes da Tabela 1. De fato, com os dados originais da Tabela 1 os níveis dos salários industriais reais em 1964 chegaram a 37,4\% dos registrados em 1961 na série 1, IPC-MTb, 14,3\% na série 2, IPC-SP, e 17,4\% na série IPA-DI.

Ainda assim, os níveis dos salários reais da Tabela 2 são não apenas apreciáveis diante da instabilidade econômica e da alta inflação do início dos anos 1960, mas na maior parte das vezes são significativamente superiores aos níveis salariais observados durante o período desenvolvimentista do governo Kubitschek. A exceção relativa foi o salário-consumo real obtido pelo uso do IPC-SP como deflator (série 2). Há indícios portanto de que, após um crescimento lento e irregular durante a maior parte da década de 1950, os salários industriais apresentaram uma tendência de elevação nos primeiros anos da década de 1960. Se isso de fato ocorreu, o resultado é digno de nota tendo em vista o ritmo acelerado da inflação e a desaceleração do crescimento econômico na época.

\section{SALÁRIOS INDUSTRIAIS NO PERÍODO 1965-1978}

Todas as séries de salário-consumo sofreram uma inflexão após o auge em 1963-1964, como é possível ver na Tabela 1. A começar pela série 1, IPC-MTb, o salário-consumo caiu sucessivamente, de forma que em 1967 chegou a apenas $79,3 \%$ do seu nível de 1964. O salário-consumo deflacionado pelo IPC-SP teve uma queda menos acentuada, sendo que em 1967 atingiu 93,1\% do valor de 1964. Já o comportamento do salário-produto (série 3, IPA-DI) divergiu do observado nas duas séries de salário-consumo ao chegar em 1967 a um nível 4,6\% superior ao de 1964.

A queda no salário-consumo entre 1965-1967 foi similar à observada anteriormente no período do governo Dutra. O novo governo militar liderado pelo marechal Castello Branco (abril 1964 - março 1967) interveio em sindicatos, perseguiu ativistas de esquerda e tornou as greves legais virtualmente impossíveis. Ao mesmo tempo, a política deflacionária adotada pelo governo visou explicitamente a compressão dos salários. Tal política foi implementada por uma regra em que o cálculo dos novos salários nominais do setor privado passou a basear-se na média dos salários reais nos 24 meses passados mais estimativas da produtividade passada e da inflação futura. Esse mecanismo de correção dos salários nominais, além da inflação futura ter sido subestimada nas estimativas oficiais, 
contribuiu para uma redução absoluta do salário-consumo na indústria manufatureira. ${ }^{13}$

Uma política antissindical similar foi implementada pelo governo Costa e Silva (março 1967 - agosto 1969). A única mudança sensível foi a modificação na fórmula de correção salarial, que a partir de junho de 1968 passou a incluir uma cláusula para compensar a subestimativa da inflação futura contida no sistema anterior (Lago et al., 1979, p. 73). Paralelamente, adotou-se desde o início de 1967 uma política macroeconômica mais flexível, que produziu maiores taxas de crescimento do produto já em 1968 (Macarini, 2006). O salário-consumo acompanhou as novas condições econômicas, com aumentos em 1968 e 1969. Ainda assim, ao final do governo Costa e Silva (1969) os salários industriais permaneceram abaixo do nível alcançado em 1964 ou o superaram apenas marginalmente, conforme o deflator utilizado. No caso do IPC-MTb (série 1), os salários reais de 1969 ficaram em $87,8 \%$ do nível de 1964 . O salário-consumo medido pelo IPC-SP apresentou em 1969 uma pequena variação positiva de 1,6\% em relação a 1964 (Tabela 1).

Do ponto de vista das empresas, os salários industriais cresceram substancialmente mais do que os rendimentos dos trabalhadores. Em 1969, o salário-produto foi superior em 19,2\% do nível registrado em 1964 . Se, de um lado, o custo salarial medido pelo salário-produto cresceu de forma substancial (14,0\%) entre 1967 e 1969 , por outro lado tal aumento indica que a compressão salarial mantida pelo governo Costa e Silva beneficiou diretamente as empresas, visto que parece razoável supor que sem ela os custos salariais tenderiam a ser significativamente maiores. De qualquer modo, a situação efetiva das empresas industriais somente pode ser avaliada considerando a produtividade do trabalho, o que será feito na próxima seção.

O governo Médici (outubro 1969 - março 1974) reforçou o controle sobre as organizações dos trabalhadores e o sistema político, elevando a repressão a um nível inédito (Gaspari, 2002). Paralelamente, o governo Médici deu continuidade às políticas monetárias e fiscais que já vinham sendo implementadas desde 1967. O período foi marcado por elevadas taxas de crescimento econômico e industrial, mas os benefícios em termos de rendimentos foram uma vez mais relativamente limitados para os trabalhadores industriais (Lago, 1990). O salário-consumo até mesmo caiu ou estagnou-se em termos reais em 1970, ocorrendo no restante do governo Médici somente um crescimento modesto e errático. O salário-consumo medido pela série 1 (IPC-MTb) não havia ainda em 1973 alcançado os níveis de 1964. O salário-consumo da série 2 (IPC-SP) apresentou um desempenho relativamente melhor, tendo chegado em 1973 a 14,7\% acima do nível de 1964. O salário-produto (série 3, IPA-DI) teve comportamento similar ao do último indicador (Tabela 1).

O governo Geisel (março 1974 - março 1979) continuou a política de desmobilização sindical, embora o regime tenha começado nesta época a confrontar os seus maiores desafios até então na forma de vitórias eleitorais da oposição civil (em 1974 e 1978) e greves de grande repercussão (em 1978) realizadas pelos trabalhadores metalúrgicos da Grande São Paulo. A Lei n. 6.147 de 29/11/1974, que esta-

${ }^{13}$ Fishlow (1973), pp. 24-30; Fishlow (2005), pp. 7-8; Lago et al. (1979), pp. 70-71, 193; e Resende (1990). 
beleceu novas regras de correção salarial, implicitamente reconheceu as perdas salariais causadas pelo sistema de reajustes vigente. Pelas novas regras, em vez do período de 24 meses previsto na antiga fórmula, os reajustes passaram a levar em conta a média dos salários reais nos últimos 12 meses. Além disso, o governo criou um "fator de ajustamento salarial" com o fim de compensar os trabalhadores pelas subestimativas de inflação anteriores (Lago et al., 1979, p. 196). Embora tenha arrefecido após 1973, o crescimento econômico entre 1974 e 1978 continuou expressivo levando em conta a recessão que a economia mundial viveu à época. ${ }^{14}$ Por sua vez, os salários industriais cresceram em todas as séries estimadas entre 1974 e 1978: a taxa média de crescimento anual do salário-consumo da série 1 (IPC-MTb) foi de $5,8 \%$ e a da série 2 (IPC-SP) atingiu 7,1\%. O salário-produto (série 3, IPA-DI) elevou-se em 6,0\% entre 1974 e 1978 (Tabela 1).

De maneira geral, uma característica do período 1945-1978 foi a intervenção recorrente nas questões trabalhistas por diferentes governos, em particular durante a administração Dutra e o regime militar. Também vale notar a ausência de uma associação direta entre governos considerados populistas ou desenvolvimentistas pela historiografia e altas taxas de crescimento real do salário industrial (salário-consumo), tanto no caso do governo Vargas quanto no governo Kubitschek. Por outro lado, parece que o salário-consumo cresceu substancialmente no início da década de 1960, apesar das dificuldades em sua medida que foram mencionadas antes. De qualquer modo, os salários industriais sofreram uma acentuada queda nos anos iniciais do regime militar e somente começaram a recuperar-se moderadamente a partir de 1968. Mesmo as altas taxas de crescimento econômico resultantes de políticas macroeconômicas ativas e do crescente endividamento externo levaram um período relativamente longo para que fossem traduzidas em aumentos apreciáveis dos salários reais na indústria manufatureira.

Apesar das conclusões gerais que podem ser obtidas exclusivamente com a análise das séries de salários reais, a avaliação das tendências na distribuição da renda industrial permanece incompleta enquanto não for considerado o desempenho da produtividade da trabalho, tema das próximas seções.

\section{CUSTOS UNITÁRIOS DO TRABALHO E DISTRIBUIÇÃO ENTRE LUCROS E SALÁRIOS}

O custo unitário do trabalho ULC mede o custo do trabalho da empresa ao produzir uma unidade de produto, sendo definido pela razão entre salário real $w$ e produtividade do trabalho $l p$, ou seja:

$$
U L C=\frac{w}{l p}
$$

\footnotetext{
${ }^{14}$ Carneiro (1990). O PIB e o valor adicionado da indústria manufatureira no Brasil cresceram em média $6,9 \%$ e $6,7 \%$ a.a. entre 1974 e 1978 , segundo dados do Oxlad.
} 
Por sua vez, a participação $u$ dos salários no produto é dada por:

$$
u=\frac{w l}{q}
$$

em que $l$ é o número de trabalhadores ocupados e $q$ o valor adicionado da produção. Naturalmente, o produto $w l$ é a folha ou massa de salários.

Se definirmos a produtividade do trabalho $l p$ como o produto por trabalhador ocupado:

$$
l p=\frac{q}{l}
$$

então a participação do salário no produto, equação (2), pode ser reescrita como:

$$
u=\frac{w}{l p}
$$

ou seja, como a razão entre o salário dos trabalhadores e a produtividade do trabalho, que equivale à definição (1) de custo unitário do trabalho. ${ }^{15}$

A Tabela 3 apresenta o custo unitário do trabalho na indústria manufatureira no Brasil de 1945 a 1978 para as séries de salário-consumo e salário-produto.

A medida mais adequada para a estimativa do custo unitário do trabalho é a do salário-produto, primeiro porque essa última variável é a relevante para as empresas em suas decisões de contratar trabalho e, segundo, porque as séries de salários e produtividade são calculadas com o mesmo índice de preços (IPA-DI). Por esse motivo, a análise a seguir concentra-se na medida de custo unitário do trabalho que utiliza o salário-produto em seu cálculo (Tabela 3, série 3).

Em termos gerais, nota-se na Tabela 3 que os custos unitários do trabalho apresentaram tendência de queda ao longo do período 1945-1978. Tal resultado indica que a evolução da distribuição da renda gerada pelo setor industrial foi crescentemente desfavorável para os salários durante o pós-Segunda Guerra Mundial no Brasil. Nota-se também que a tendência de queda na participação do salário - e aumento dos lucros - na renda da indústria manifestou-se igualmente nos dois períodos de 1945-1964 e 1965-1978.

Como é possível deduzir das equações 1 e 4 acima, o declínio do custo unitário do trabalho e da participação dos salários no produto industrial no pós-guerra foi um resultado direto da evolução desigual dos salários reais e da produtividade do trabalho. As diferenças de desempenho entre os salários reais e a produtividade do trabalho podem ser mais bem visualizadas na Figura 1, que reproduz índices $(1952=100)$ do salário-produto, da produtividade do trabalho e do custo unitário do trabalho calculados a partir da Tabela 1.

${ }^{15}$ Decorre das definições acima que a participação dos lucros no produto é dada por $1-\frac{w}{p}$. 
Tabela 3: Custos unitários do trabalho do pessoal ligado à produção na indústria manufatureira, Brasil, 1945-1978

\begin{tabular}{|c|c|c|c|}
\hline Ano & $\begin{array}{l}\text { Custo Unitário do } \\
\text { Trabalho } \\
\text { (IPC-MTb) } \\
\text { (1) }\end{array}$ & $\begin{array}{l}\text { Custo Unitário do } \\
\text { Trabalho } \\
\text { (IPC-SP) } \\
\text { (2) }\end{array}$ & $\begin{array}{l}\text { Custo Unitário do } \\
\text { Trabalho } \\
\text { (IPA-DI) } \\
\text { (3) }\end{array}$ \\
\hline 1945 & 0,305 & 0,285 & 0,247 \\
\hline 1946 & 0,326 & 0,305 & 0,265 \\
\hline 1947 & 0,240 & 0,225 & 0,234 \\
\hline 1948 & 0,228 & 0,213 & 0,225 \\
\hline 1949 & 0,227 & 0,232 & 0,230 \\
\hline 1950 & 0,237 & 0,240 & 0,239 \\
\hline 1951 & 0,247 & 0,249 & 0,249 \\
\hline 1952 & 0,258 & 0,258 & 0,258 \\
\hline 1953 & 0,238 & 0,221 & 0,233 \\
\hline 1954 & 0,255 & 0,237 & 0,237 \\
\hline 1955 & 0,250 & 0,235 & 0,236 \\
\hline 1956 & 0,248 & 0,236 & 0,236 \\
\hline 1957 & 0,234 & 0,227 & 0,236 \\
\hline 1958 & 0,212 & 0,203 & 0,213 \\
\hline 1959 & 0,204 & 0,183 & 0,185 \\
\hline 1960 & 0,205 & 0,181 & 0,184 \\
\hline 1961 & 0,206 & 0,179 & 0,183 \\
\hline 1962 & 0,208 & 0,177 & 0,182 \\
\hline 1963 & 0,226 & 0,180 & 0,184 \\
\hline 1964 & 0,243 & 0,175 & 0,185 \\
\hline 1965 & 0,200 & 0,154 & 0,171 \\
\hline 1966 & 0,167 & 0,137 & 0,158 \\
\hline 1967 & 0,172 & 0,145 & 0,172 \\
\hline 1968 & 0,164 & 0,138 & 0,165 \\
\hline 1969 & 0,159 & 0,133 & 0,164 \\
\hline 1970 & 0,128 & 0,109 & 0,134 \\
\hline 1971 & 0,140 & 0,120 & 0,147 \\
\hline 1972 & 0,153 & 0,132 & 0,162 \\
\hline 1973 & 0,144 & 0,124 & 0,151 \\
\hline 1974 & 0,141 & 0,120 & 0,141 \\
\hline 1975 & 0,140 & 0,118 & 0,144 \\
\hline 1976 & 0,147 & 0,128 & 0,149 \\
\hline 1977 & 0,149 & 0,133 & 0,155 \\
\hline 1978 & 0,150 & 0,137 & 0,159 \\
\hline
\end{tabular}

Nota: Custo Unitário do Trabalho obtido pela equação 1 no texto, em que $w=$ salários do pessoal ocupado na produção, $p$ = produtividade do pessoal ocupado na produção, com os dados da Tabela 1.

Fonte: Tabela 1. 
Figura 1: Salário médio, produtividade e custo unitário do trabalho no Brasil, 1945-1978

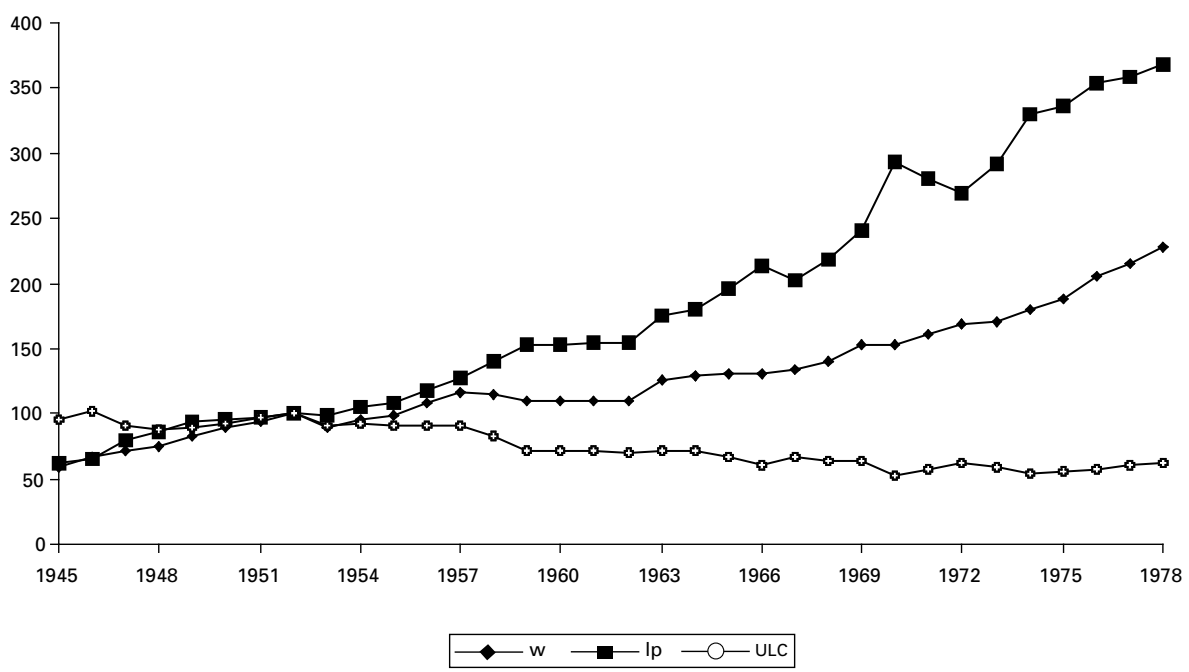

Nota: $w$ = salário-produto do pessoal ocupado na produção; $l p=$ produtividade do pessoal ocupado na produção; ULC = custo unitário do trabalho.

Fonte: Tabela 1.

A Figura 1 mostra que os níveis do salário-produto tenderam a ficar abaixo dos alcançados pela produtividade do trabalho na maior parte do período 1945-1978. É possível ver também que o salário-produto acompanhou em certa medida o crescimento da produtividade do trabalho até 1957 , tendo as trajetórias das duas variáveis divergido drasticamente a partir de então. A taxa média de crescimento do salário-produto foi de apenas $1,8 \%$ a.a. enquanto a da produtividade do trabalho chegou a 5,2\% a.a. entre 1958 e $1968 .{ }^{16} \mathrm{O}$ crescente hiato entre as duas séries da Figura 1 indica que os elevados ganhos de produtividade registrados a partir de 1954 foram principalmente absorvidos pelas empresas na forma de lucros, levando a uma distribuição da renda industrial cada vez mais desfavorável aos trabalhadores.

A crescente divergência entre salários e produtividade já na segunda metade da década de 1950 pode ter tido um impacto direto sobre as relações de trabalho na indústria brasileira. Um dos possíveis resultados da ampliação do hiato entre lucros e salários na indústria foi que se tornou cada vez mais difícil a acomodação dos interesses entre industriais e trabalhadores organizados, minando as bases de um "pacto de crescimento" que pudesse combinar o rápido crescimento econômico observado na época com reformas sociais e distribuição de renda. Dessa forma, o aumento da desigualdade na distribuição da renda industrial pode ter reforçado um padrão de relações de trabalho já altamente confrontacional que emergiu no

\footnotetext{
${ }^{16}$ Estas e todas as taxas de crescimento dos salários e da produtividade do trabalho citadas a seguir foram calculadas a partir da Tabela 1 .
} 
imediato pós-guerra e que se tornou ainda mais acirrado com as disputas entre campos ideológicos opostos da Guerra Fria (Colistete, 2007).

\section{CUSTOS UNITÁRIOS DO TRABALHO NO PERÍODO 1945-1964}

A elevação de salários em 1946 vista nas séries da Tabela 1 foi superior ao aumento ocorrido na produtividade do trabalho, resultando em uma elevação geral do custo unitário do trabalho naquele ano. Por outro lado, com uma elevação estimada de $21,2 \%$ na produtividade do trabalho em 1947, houve nesse último ano uma expressiva diminuição do custo unitário do trabalho. ${ }^{17}$ Nota-se, portanto, que as políticas econômicas deflacionárias e a repressão aos sindicatos implementadas pelo governo Dutra tiveram, aparentemente, um efeito negativo direto sobre a participação dos salários na renda da indústria manufatureira (Tabela 3, série 3). ${ }^{18}$

A recuperação salarial que ocorreu durante o governo Dutra, surpreendente dadas a ausência de reajuste do salário mínimo e a política repressiva adotada, não foi suficiente para deter a queda $(-3,8 \%)$ no custo unitário do trabalho em 1948 , devido ao aumento ocorrido na produtividade do trabalho (Tabela 3, série 3). Ainda assim, a partir de 1949 o ritmo de aumento dos salários foi maior do que o da produtividade, fazendo com que os custos unitários do trabalho se elevassem, embora sem recuperar os níveis anteriores a 1947, conforme pode ser visto na Tabela 3.

Já durante o governo Vargas, houve inicialmente crescimento no custo unitário do trabalho, refletindo resultados favoráveis aos trabalhadores $(3,6 \%$ em 1951 e 1952; Tabela 3, série 3). Mas em seguida a queda nos salários reais compensou o declínio ocorrido na produtividade do trabalho, levando a uma redução no custo unitário do trabalho de $-9,7 \%$ em 1953 (Tabela 3, série 3). Essa queda fez com que o nível do custo unitário do trabalho fosse inferior ao alcançado em 1950, último ano do governo Dutra. Além disso, a elevação do custo unitário do trabalho em 1954 foi bem menos significativa $(1,7 \%)$ do que a ocorrida no salário-produto $(8,4 \%)$ devido ao expressivo aumento da produtividade do trabalho $(6,5 \%)$ (Tabela 3, série 3). Ao final do governo Vargas, o custo unitário do trabalho ficou abaixo do registrado no seu primeiro ano ou mesmo inferior ao do último ano do governo Dutra. Se consistente, esse resultado reforça uma perspectiva mais pessimista do que a usual quanto aos resultados das políticas governamentais da época, muitas vezes vistas pela historiografia como favoráveis aos trabalhadores. ${ }^{19}$

A queda dos custos unitários do trabalho foi ainda maior durante a segunda

\footnotetext{
${ }^{17}$ Dada a sua magnitude, a estimativa da produtividade em 1947 deve ser vista com cautela. O mesmo alerta se aplica a outras estimativas a seguir em anos específicos, como em 1970-1972.

${ }^{18}$ Sobre o contexto de mobilização dos trabalhadores no imediato pós-guerra ver Maranhão (1979); French (1992); Wolfe (1993); Costa (1995); e Colistete (2001).

${ }^{19}$ Ver, por exemplo, Almeida (1986), pp. 250-253; Carone (1985), p. 54; Mendonça (2000), pp. 333, 342-343; Rodrigues (1986), p. 555.
} 
metade da década de 1950. Os custos unitários do trabalho mantiveram-se praticamente constantes nos primeiros anos do governo Kubitschek, mas em seguida houve reduções sucessivas no indicador: $-9,7 \%$ em $1958,-13,1 \%$ em 1959 e $-0,5 \%$ em 1960. No último ano do governo Kubitschek (1960), o nível do custo unitário do trabalho chegou a apenas $78,0 \%$ do registrado no primeiro ano do governo (1956) (Tabela 3, série 3). O declínio acentuado dos custos unitários do trabalho e da participação dos trabalhadores na renda industrial no período refletiu a disparidade das taxas médias de crescimento do salário-produto e da produtividade do trabalho, que foram, respectivamente, $2,2 \%$ e $7,3 \%$ em 1956 e 960 . Tal resultado é notável diante das altas taxas de crescimento econômico que caracterizaram a idade de ouro do desenvolvimentismo na segunda metade da década de $1950 .{ }^{20}$

O que ocorreu com os custos unitários do trabalho no período crítico dos governos Jânio Quadros e João Goulart, entre 1961 e 1964? A estimativa dos custos do trabalho e da distribuição entre salários e lucros industriais nesse período é mais difícil devido à mudança na definição do conceito de "pessoal ligado à produção", já comentada anteriormente. Mas, como foi visto, aparentemente houve um aumento importante dos salários industriais reais em 1963, mesmo quando são estimados limites superiores e inferiores ajustados em relação às séries originais. Parece relevante, então, adotar o mesmo procedimento utilizado na análise dos salários reais para estimar o que pode ter ocorrido com os custos unitários do trabalho nos anos 1963-1964.

No conjunto do período, a distribuição entre lucros e salários industriais permaneceu praticamente estável, sendo que houve apenas um aumento de $1,1 \%$ nos níveis dos custos unitários do trabalho em 1964 em relação a 1961. A estabilidade relativa na participação dos salários na renda do setor industrial é digna de nota, dado o expressivo aumento dos salários reais registrado em 1963 nas séries originais da Tabela 1. A manutenção da distribuição de salários e lucros em meio a uma conjuntura de significativa elevação dos salários somente tornou-se possível graças aos $13,6 \%$ de aumento da produtividade do trabalho em 1963 (Tabela 1, colunas 3 e 4$)$.

O quadro torna-se mais vantajoso para as empresas, e mais desvantajoso para os trabalhadores, se a análise for baseada nos limites inferiores e superiores estimados na Tabela 4.

No caso da série 3 (IPA-DI) da Tabela 4, o limite superior do custo unitário do trabalho diminuiu $-7,7 \%$ em 1963 e teve uma pequena elevação de 1,2\% em 1964. Já o limite inferior do custo unitário do trabalho caiu -9,9\% em 1963 e -1,8\% em 1964. Portanto, em ambas as estimativas que tentam descontar o efeito das mudanças na metodologia das estatísticas oficiais, o custo unitário do trabalho declinou no início da década de 1960 . Nesse caso, o comportamento dos custos unitários do trabalho teria sido muito mais favorável para as empresas - e prejudicial para os trabalhadores - do que sugerido pelos cálculos anteriores que utilizaram os dados originais.

\footnotetext{
${ }^{20}$ Ver também Fishlow (1972), pp. 56-57; Hoffman (1975), pp. 110-111.
} 
Tabela 4: Estimativas dos custos unitários do

trabalho na indústria manufatureira, Brasil, 1963-1964

\begin{tabular}{|c|c|c|c|c|c|c|}
\hline \multirow{2}{*}{ Ano } & \multicolumn{2}{|c|}{$\begin{array}{l}\text { Custo Unitário } \\
\text { do Trabalho } \\
\text { (IPC MTb) } \\
\text { (1) }\end{array}$} & \multicolumn{2}{|c|}{$\begin{array}{l}\text { Custo Unitário } \\
\text { do Trabalho } \\
\text { (IPC-SP) } \\
\text { (2) }\end{array}$} & \multicolumn{2}{|c|}{$\begin{array}{l}\text { Custo Unitário } \\
\text { do Trabalho } \\
\text { (IPA-DI) } \\
\text { (3) }\end{array}$} \\
\hline & $\begin{array}{l}\text { Limite } \\
\text { superior }\end{array}$ & $\begin{array}{l}\text { Limite } \\
\text { inferior }\end{array}$ & $\begin{array}{l}\text { Limite } \\
\text { superior }\end{array}$ & $\begin{array}{l}\text { Limite } \\
\text { inferior }\end{array}$ & $\begin{array}{l}\text { Limite } \\
\text { superior }\end{array}$ & $\begin{array}{l}\text { Limite } \\
\text { inferior }\end{array}$ \\
\hline 1963 & 0,217 & 0,202 & 0,165 & 0,161 & 0,168 & 0,164 \\
\hline 1964 & 0,234 & 0,212 & 0,161 & 0,153 & 0,170 & 0,161 \\
\hline
\end{tabular}

Fonte: Ver texto.

\section{CUSTOS UNITÁRIOS DO TRABALHO NO PERÍODO 1965-1978}

Medido pelo salário-produto, o custo unitário do trabalho caiu sucessivamente durante o governo Castello Branco, sendo que ao seu final (1966) o nível do custo do trabalho atingiu $85,4 \%$ do registrado em 1964 (Tabela 3, série 3). Novamente, tal queda refletiu o aumento da produtividade do trabalho em contraste com a relativa estagnação dos salários reais. Parece claro que as políticas econômicas e de repressão ao movimento sindical promovidas pelo governo militar foram responsáveis por uma forte contenção dos salários reais que beneficiou diretamente as empresas do setor industrial. ${ }^{21}$

O início do governo Costa e Silva foi marcado por uma elevação do custo unitário do trabalho, que no entanto foi revertida nos anos seguintes (Tabela 3, série 3). O expressivo aumento da produtividade (8,3\% em 1968 e 9,8\% em 1969) permitiu que, mesmo com o aumento no salário-produto observado em uma época em que a economia já se encontrava em plena recuperação, fosse mantida a tendência de distribuição regressiva da renda gerada pela indústria manufatureira. ${ }^{22}$

Durante o governo Médici, o custo unitário do trabalho teve uma queda acentuada $(-18,3 \%)$ em 1970, acompanhada de aumentos substanciais de 9,7\% em 1971 e 1972 e nova redução de $-6,8 \%$ em 1973 (Tabela 3, série 3). Os aumentos dos custos do trabalho em 1971 e 1972 estão diretamente relacionados às quedas absolutas da produtividade constatadas nesses anos. Porém, a retomada da produtividade do trabalho $(8,3 \%)$ em 1973 foi suficiente para superar o baixo crescimento do salário-produto $(1,0 \%)$ naquele ano, levando a uma nova queda do custo unitário do trabalho. Assim, os custos unitários do trabalho em 1973,

\footnotetext{
${ }^{21}$ Essas evidências para os anos 1965-1966 convergem com as tendências identificadas por Fishlow (1973), pp. 27-28.

${ }^{22}$ Conforme argumentou Fishlow (1973), “[o] continuado caráter regressivo da política salarial após 1967 não deve ficar obscurecido pela atenção a declínios anteriores e subsequente estabilidade, ou mesmo aumentos, nos salários industriais. O relevante é a comparação com a produtividade [...]" (p. 29).
} 
final do governo Médici, chegaram a apenas $92,1 \%$ do nível alcançado no início desse governo, em 1969. Além disso, o custo unitário do trabalho atingiu em 1970 seu menor nível na série histórica da Tabela 3, coluna 3. Ampliando o horizonte de comparação, em 1973 o nível do custo unitário do trabalho foi apenas 81,6\% do registrado em 1964. De maneira geral, portanto, a distribuição entre salários e lucros tornou-se mais desfavorável aos trabalhadores industriais no período 1965-1973, apesar do elevado crescimento do produto industrial nos anos do "milagre econômico". ${ }^{23}$

Como notado anteriormente, o período do governo Geisel foi caracterizado pelo aumento dos salários reais. O efeito desse forte aumento dos salários industriais, porém, foi atenuado pela elevação verificada na produtividade do trabalho. Em 1974, o crescimento do custo unitário do trabalho foi negativo (-6,6\%), apesar do aumento $(5,9 \%)$ do salário-produto. O excepcional crescimento da produtividade $(13,2 \%)$ naquele ano garantiu a redução do custo do trabalho em meio à elevação salarial. Nos anos seguintes, houve mudança nessa tendência. Olhando o período Geisel como um todo, o nível do custo unitário do trabalho situou-se, em $1978,5,3 \%$ acima do observado em 1973 . Nota-se que a diferença da evolução do custo unitário do trabalho entre o período Geisel e o período 1965-1973 deveu-se à alteração simultânea nas tendências de comportamento do salário-produto e da produtividade do trabalho.

Ainda assim, a vantagem obtida pelos trabalhadores em termos distributivos nos anos 1974-1978 foi bastante limitada, sobretudo se for considerado o período 1965-1978 como um todo. Não só o aumento do custo unitário do trabalho foi pequeno em termos absolutos se comparados o início e o final do governo Geisel, conforme mostrado acima; além disso, os níveis do custo do trabalho em 1978 situaram-se ainda substancialmente abaixo do alcançado em 1964, a partir de quando houve a mudança no regime político e passaram a ser adotadas políticas de compressão salarial e de repressão contra os trabalhadores organizados. Mesmo com a elevação ocorrida nos anos do governo Geisel, os custos unitários do trabalho em 1978 chegaram a apenas 85,9\% do nível alcançado em 1964.

\section{CONCLUSÕES}

A constatação pela historiografia de que a industrialização acelerada no pós-guerra no Brasil foi marcada por níveis elevados de concentração da renda pessoal, com pioras significativas em determinados períodos, é confirmada pelos dados relativos à distribuição funcional da renda no setor industrial. A distribuição entre salários e lucros industriais variou significativamente, mas apresentou uma tendência de aumento da desigualdade nas décadas de 1940 e 1950. Os dados sugerem uma visão pessimista quanto aos efeitos do populismo durante o governo Vargas, pelo menos em termos da transferência aos trabalhadores dos benefícios

${ }^{23}$ Ver também Lago et al. (1979), pp. 173-174. 
do crescimento industrial do período. Uma conclusão similar pode ser estendida ao governo Kubitschek, durante o período áureo do desenvolvimentismo.

O período que se inicia em 1964 reafirmou e aprofundou a tendência de aumento da desigualdade entre lucros e salários industriais. Durante os governos militares de Castello Branco, Costa e Silva e Médici houve um marcante declínio das participações dos salários na renda industrial, apesar do excepcional crescimento econômico que se iniciou em 1968. Foi somente durante o governo Geisel, entre 1974 e 1978, que ocorreu uma reversão daquela tendência, embora apenas marginal. Comparada à situação existente no início do regime militar, a distribuição da renda industrial em 1978 ainda se manteve significativamente mais desigual do que catorze anos antes, em 1964.

Tais resultados sugerem que explicações da evolução desigual da distribuição entre lucros e salários industriais no Brasil do pós-guerra necessitam levar em conta, em primeiro lugar, as causas do desempenho notável da produtividade do trabalho a partir de meados da década de 1950. Aparentemente, a rápida diversificação industrial no Brasil no pós-guerra não se limitou apenas a uma expansão quantitativa, tendo havido ganhos importantes em termos de eficiência nos processos produtivos que se traduziram nos aumentos observados da produtividade do trabalho. Em segundo lugar, é necessário buscar compreender as causas institucionais e políticas que impediram que os ganhos de produtividade fossem repassados aos trabalhadores industriais, como aconteceu em outras sociedades no pós-guerra. Desde o final da Segunda Guerra Mundial até o início da década de 1960, um padrão altamente conflitivo das relações de trabalho parece ter minado as bases para uma acomodação de interesses entre trabalhadores organizados e industriais que permitisse combinar rápido crescimento econômico com uma distribuição mais igualitária da renda. A resolução do conflito distributivo deu-se por meio de uma mudança radical do sistema político em 1964 que consolidou tendências seculares de profunda desigualdade na distribuição da riqueza e da renda no Brasil.

\section{APÊNDICE}

\section{Fontes}

Os dados de salários/número de trabalhadores ligados à produção, valor da transformação industrial e índices de preços utilizados no artigo foram extraídos das seguintes fontes:

\section{Salários e produtividade do trabalho:}

1945-1948: salários e número do pessoal ligado à produção obtidos por extrapolação dos dados de IBGE, Censo Industrial de 1950 (ano de 1949), utilizando as taxas de crescimento dos salários e trabalhadores divulgados pelo IAPI. Valor da transformação industrial obtido por interpolação entre os dados de 
IBGE, Censo Industrial de 1940 (ano de 1939) e 1950 (ano de 1949) (Brasil, 1990).

1949 e 1959: IBGE, Censo Industrial de 1950 e 1960, dados da indústria de transformação, conforme Brasil (1990).

1952-1958, 1962: IBGE, Registro Industrial, dados da indústria de transformação, conforme IBGE, Anuários Estatísticos do Brasil de 1955, 1956, 1957, 1958, 1959, 1960 e 1965.

1963-1965: IBGE, Pesquisa Industrial, dados da indústria de transformação, conforme IBGE, Anuários Estatísticos do Brasil de 1966 e 1967.

1966-1969: IBGE, Pesquisa Industrial, dados da indústria de transformação, conforme IBGE, Anuários Estatísticos do Brasil de 1970 e 1971.

1970, 1972-1978: IBGE, Pesquisa Industrial Anual, dados da indústria de transformação, conforme Brasil (1990).

1950, 1951, 1960, 1961, 1971: valores estimados por interpolação linear.

\section{Índices de preços:}

Índice de Preços ao Consumidor do Ministério do Trabalho (IPC-MTb): média anual, 1948-1978, conforme Brasil (1990), tabela 5.4. A série foi complementada nos anos 1945-1947 usando a taxa de variação do Índice de Preços ao Consumidor da Prefeitura de São Paulo, reproduzido em Brasil (1990), tabela 5.16 .

Índice de Preços ao Consumidor do Município de São Paulo (IPC-SP), da Prefeitura de São Paulo (até 1968) e Instituto de Pesquisas Econômicas - IPE-USP (de 1968 em diante): média anual, 1945-1978, conforme Brasil (1990), tabela 5.16.

Índice de Preços ao Atacado - Disponibilidade Interna, da Fundação Getulio Vargas (IPA-DI): média anual, 1945-1978, conforme Brasil (1990), tabela 5.12.

\section{REFERÊNCIAS BIBLIOGRÁFICAS}

ABREU, Marcelo P. “Inflação, estagnação e ruptura: 1961-1964”, in Marcelo de Paiva Abreu (org.). A ordem do progresso. Cem anos de política econômica republicana, 1889-1989. Rio de Janeiro: Campus, 1990.

ALMEIDA Jr., Antonio M. "Do declínio do Estado Novo ao suicídio de Getulio Vargas", in Boris Fausto (org.). História geral da civilização brasileira. O Brasil Republicano. Sociedade e política (1930-1964). $3^{\text {a }}$ ed., Difel: 1986, tomo III, vol. 3.

ALTIMIR, Oscar. "Economic development and social equity". Journal of Interamerican Studies and World Affairs. 38 (2/3), Summer/Autumn 1996: 47-71.

BACHA, Edmar. "Crescimento econômico, salários urbanos e rurais: o caso do Brasil”. Pesquisa \& Planejamento Econômico. 9 (3), dezembro 1979: 585-628.

BARROS, Ricardo Paes et al. "Bem-estar, pobreza e desigualdade de renda: uma avaliação da evolução histórica e das disparidades regionais”. Textos para Discussão - IPEA, n. 454, janeiro 1997.

BRASIL. Anuário estatístico do Brasil. Rio de Janeiro: IBGE, vários anos. 
BRASIL. Estatísticas históricas do Brasil. Séries econômicas, demográficas e sociais, 1550 a 1988. 2a ed., Rio de Janeiro: IBGE, 1990.

CARLIN, Wendy \& SOSKICE, David. Macroeconomics. Imperfections, institutions and policies. Oxford: Oxford University Press, 2006.

CARNEIRO, Dionísio D. “Crise e esperança: 1974-1980”, in Marcelo de Paiva Abreu (org.). A ordem do progresso. Cem anos de política econômica republicana, 1889-1989. Rio de Janeiro: Campus, 1990.

CARONE, Edgar. A República liberal. Evolução política (1945-1964). São Paulo: Difel, 1985.

COLISTETE, Renato P. "Productivity, wages, and labor politics in Brazil, 1945-1962". Journal of Economic History. 67 (1), March 2007: 93-127.

COLISTETE, Renato P. Labour relations and industrial performance in Brazil, 1945-1960. Houndmills: Palgrave/Macmillan, 2001.

CONSIDERA, Claudio. "Estrutura e evolução dos lucros e dos salários na indústria de transformação”. Pesquisa \& Planejamento Econômico. 10 (1), abril 1980: 71-122.

CORNIA, Giovanni \& ADDISON, Tony. "Income distribution changes and their impact in the post-World War II period”. United Nations University Discussion Papers. March 2003, n. 2003/28.

COSTA, Hélio. Em busca da memória. Comissão de fábrica, partido e sindicato no pós-guerra. São Paulo: Scritta, 1995.

DEININGER, Klaus \& SQUIRE Lyn. "A new data set measuring income inequality”. The World Bank Economic Review. 10(3), 1996: 565-91.

FISHLOW, Albert. "Origens e consequências do processo de substituição de importações no Brasil”. Estudos Econômicos. (2) 6, dezembro 1972: 7-75.

FISHLOW, Albert. "Distribuição de renda no Brasil - um novo exame”. Dados. 11, 1973: 10-80

FISHLOW, Albert. "Thirty years of combating inflation in Brazil: from the PAEG (1964) to the Plano Real (1994)", Centre for Brazilian Studies Working Papers. University of Oxford, n. 68-05, May 2005.

FISHLOW, Albert \& CARDOSO, Eliana. "Latin American economic development: 1950-1980”. Journal of Latin American Studies. 24, 1992: 197-218.

FRENCH, Jonh. The Brazilian workers' ABC: class conflict and alliances in modern São Paulo. Chapel Hill: University of North Carolina Press, 1992.

GASPARI, Elio. As ilusões armadas - A ditadura escancarada. São Paulo: Companhia das Letras, 2002.

HOFFMAN, Rodolfo. "Tendências da distribuição da renda no Brasil e suas relações com o desenvolvimento econômico", in Ricardo Tolipan e Arthur C. Tinelli (ed.). A controvérsia sobre distribuição de renda e desenvolvimento. Rio de Janeiro: Zahar, 1975.

HOFFMAN, Rodolfo. "Distribuição de renda e crescimento econômico". Estudos Avançados. 15 (41), janeiro-abril 2001: 67-76.

LAGO, Luiz Aranha Corrêa. “A retomada do crescimento e as distorções do 'milagre', 1967-1973”, in Marcelo de Paiva Abreu (org.). A ordem do progresso. Cem anos de política econômica republicana, 1889-1989. Rio de Janeiro: Campus, 1990.

LAGO, Luiz Aranha Corrêa et al. O sistema de relações trabalhistas no Brasil e suas implicações econômicas e sociais, 1940-1979. Rio de Janeiro: IBRE-FGV, 1979.

MACARINI, José P. “A política econômica do governo Costa e Silva 1967-1969”. Revista de Economia Contemporânea. 10 (3), setembro-decembro 2006.

MADDISON, Angus et al. The political economy of poverty, equity and growth. Brazil and Mexico. Oxford: Oxford University Press, 1992.

MARANHÃO, Ricardo. Sindicato e democratização: Brasil, 1945-1950. São Paulo: Brasiliense, 1979.

MATA, Milton e BACHA, Edmar. "Emprego e salários na indústria de transformação, 1949/1969”. Pesquisa \& Planejamento Econômico. 3 (2), junho 1973: 305-340.

MENDONÇA, Sônia R. “As bases do desenvolvimento capitalista dependente: da industrialização 
restringida à internacionalização”, in Maria Yedda Linhares (org.). História geral do Brasil. $9^{a}$ ed., Rio de Janeiro: Campus, 2000.

ÓCIO, Domingo Zurron. "Salários e política salarial”. Revista de Economia Política. 6 (2), abril-junho 1986: 5-26.

RESENDE, André L. "Estabilização e reforma: 1964-1967", in Marcelo de Paiva Abreu (org.). A ordem do progresso. Cem anos de política econômica republicana, 1889-1989. Rio de Janeiro: Campus, 1990.

RODRIGUES, Leôncio M. "Sindicalismo e classe operária", in Boris Fausto (org.). História geral da civilização brasileira. O Brasil Republicano. Sociedade e política (1930-1964). 3a ed., Difel: 1986, tomo III, vol. 3 .

SABOIA, João. "Salários e produtividade na indústria brasileira: os efeitos da política salarial no longo prazo”. Pesquisa \& Planejamento Econômico. 20 (3), dezembro 1990: 581-600.

SOUZA, Paulo Renato \& BALTAR, Paulo. "Salário mínimo e taxa de salários no Brasil”. Pesquisa \& Planejamento Econômico. 9 (3), dezembro 1979: 629-659.

TAVARES, Maria da Conceição \& SOUZA, Paulo Renato. "Emprego e salários na indústria - o caso brasileiro". Revista de Economia Política. 1 (1), janeiro-março 1981: 3-29.

THORP, Rosemary. Progresso, pobreza e exclusão: uma história econômica da América Latina no século XX. Nova York: Banco Interamericano de Desenvolvimento, 1998.

VIANNA, Sérgio B. "Política econômica externa e industrialização: 1946-1951", in Marcelo de Paiva Abreu (org.). A ordem do progresso. Cem anos de política econômica republicana, 1889-1989. Rio de Janeiro: Campus, 1990.

WELLS, John. "Distribution of earnings, growth and the structure of demand in Brazil during the 1960s”. World Development. 2 (1), January 1974: 9-24.

WELLS, John. "Industrial accumulation and living standards in the long-run: the São Paulo industrial working class, 1930-1975, Part II". Journal of Development Studies. 19, 1983: 297-328.

WOLFE, Joel. Working women, working men. São Paulo and the rise of Brazil's working-class, 1900-1955. Durham: Duke University Press, 1993. 